\title{
Cultura digital, nuevas formas de opresión, resistencia y subversión
}

María Concepción Castillo-González

Tecnológico de Monterrey, México

ORCID: 0000-0002-2892-9079

ccastill@tec.mx
Mariana Gabarrot Arenas

Tecnológico de Monterrey, México

ORCID: 0000-0001-6894-0144

mariana.gabarrot@tec.mx

\section{Presentación}

Este monográfico presenta trabajos centrados en el análisis de las sofisticadas formas de violencia y resistencia social que son configuradas y a la vez configuran la cultura digital. Se presentan casos de estudio que problematizan el desarrollo tecnológico, a partir de realidades experimentadas por grupos subalternos situados en el sur global, específicamente en América Latina y en África. Las disquisiciones realizadas por los trabajos académicos aquí expuestos se realizan desde epistemologías críticas, feministas y descoloniales.

El llamado realizado para conformar este número en Virtualis responde a la necesidad de indagar críticamente los fenómenos de opresión y resistencia que emergen en el marco de la aceleración de la digitalización de la vida cotidiana (Girardi, 2019), misma que se ha visto agudizada por el confinamiento ante la pandemia Covid19. Esta tendencia favorece los intereses del sistema capitalista, patriarcal y colonial de occidente, al reforzar los dispositivos biopolíticos de control y vigilancia (Foucault, 2001). De tal forma, se continúa cimentando una estructura edificada y robustecida a costa de subjetividades, especies y entidades que han sido reiteradamente explotadas, discriminadas y marginadas (Braidotti, 2015; Fraser, 2020; Ferrando, 2020).

Considerando que el avance tecno científico no es neutral, que los artefactos tienen política (Winner,1983) y que éstos son diseñados en su mayoría por actores hegemónicos del norte global; es ineludible reflexionar sobre la manera en que estos históricos sistemas de opresión moldean la arquitectura de la tecnología digital pero a la vez, es necesario discutir sobre la emergencia de subjetividades y movimientos sociales que están articulando inéditas formas de resistencia, a partir de las mismas lógicas planteadas por el capitalismo avanzado.

Estas resistencias son necesarias porque las nuevas formas de opresión agravan la vulnerabilidad de los subalternos quienes, por la falta de infraestructuras, tienen un limitado acceso a conocimientos especializados que les permitan acciones contestatarias, como son la programación computacional y el manejo del idioma inglés. Ambas, habilidades necesarias para identificar y enfrentar las sofisticadas violencias y 
opresiones manifiestas en y desde lo digital. Existen ya evidencias empíricas de movimientos sociales que han incorporado el trabajo de activistas especializados en programación, quienes de forma colectiva extienden la alfabetización tecnológica a sus pares y diseñan creativas estrategias tecnopolíticas de lucha (Toret, 2015), así como inéditas prácticas de resistencia algorítmica que se aprenden dentro de las mismas contiendas (Treré, 2020). Esto apunta a que la acción colectiva necesita trascender los tradicionales repertorios de lucha y fomentar una particular agencia digital, la cual permita descifrar las dominaciones incrustadas en las distintas plataformas. Para ello, se requiere de subjetividades que enarbolen proyectos políticos alternativos al paradigma transhumanista, mismo que exacerba los valores de la hegemonía occidental al celebrar de manera acrítica el desarrollo tecnológico (Braidotti, 2020).

Las temáticas y casos presentados en los artículos que forman parte de este dossier, muestran un esfuerzo académico por sistematizar y teorizar estos fenómenos sociotécnicos desde una perspectiva crítica, de ahí el llamado particular a los enfoques feministas y descoloniales. En esta introducción se contextualiza la importancia de cavilar sobre las renovadas formas de opresión y resistencia digital que hemos mencionado, para luego presentar los artículos que forman parte del monográfico.

\section{Cultura digital y nuevas formas de opresión}

El desarrollo de la tecnología digital reproduce la idea de lo que Paola Ricaurte (2019) denomina como el vigente y pujante paradigma de datos, el cual amplifica las formas históricas de colonización y opresión. En consecuencia, emergen formas de disciplinamiento del cuerpo social, tales como la represión algorítmica, la apropiación de datos y la fabricación del consentimiento (Treré, 2016), además de nuevas modalidades de violencia que posibilitan las lógicas de los entornos digitales que responden a intereses comerciales (Dragiewicz, Harris, Woodlock \& Salter, 2021). Este escenario se agudiza por la creciente plataformización de la vida social, la cual concentra el poder económico mediante una forma particular de cercamiento, caracterizada por la privatización del Internet y la marginación e incluso criminalización de los valores asociados al bien común, tal como se puede apreciar al echar un vistazo a las complicadas leyes que regulan la circulación de archivos de música o de texto (Van Dijck, 2020).

La dinámica del capitalismo actual se configura entonces a partir de la captura y procesamiento de prácticas sociales convertidas en flujos de datos digitales con fines de lucro (Mejías \& Couldry, 2019). Lo anterior explica el crecimiento desbordado del número de plataformas, así como la comercialización de aplicaciones digitales, a costa de espacios libres en Internet que favorecen la vida comunitaria. Vivimos un 
neocolonialismo a escala planetaria que, con nuevas prácticas extractivistas, se consolida en todo el mundo al fomentar relaciones instrumentales y concentrar la riqueza en las instancias que diseñan la tecnología para obtener ganancias económicas sin ninguna instancia de regulación.

Al respecto, Tendayi Achiume investigadora de la Universidad de California y relatora especial sobre racismo en las Naciones Unidas, señala que la inteligencia artificial, el reconocimiento facial, los algoritmos y abuso de macrodatos fomentan la discriminación y el control social de grupos racializados y criminalizados por su condición marginal, incluyendo las mujeres, las personas migrantes, transgenero, afrodescendientes e indígenas (ONU, 2020). Esta es una muestra de que la arquitectura digital responde a los intereses hegemónicos y favorece el robustecimiento de prácticas y representaciones sociales que recrean y complejizan la violencia social.

\section{Resistencias y subversiones tecnodigitales}

Como se ha afirmado, la infraestructura sociodigital recrea la opresión por medio de prácticas, representaciones y algoritmos que responden a las lógicas hegemónicas y es alarmante el inmenso poder que acumulan las empresas y los Estados por medio de la extracción de datos personales de millones de ciudadanos a escala global. Sin embargo, existen posibilidades de resistencia, considerando que las redes y los servicios digitales son parte de una compleja ecología mediática sociocultural que puede ser intervenida y usada como espacio de contienda política. Se trata de tácticas tecnopolíticas, que son formas "polifacéticas de acción comunicativa que combinan, de manera compleja, el conocimiento tecnológico y la pericia digital empleados para fines políticos" (Treré, 2020, p. 164). Un tipo de activismo que está tecnológicamente alfabetizado y que es capaz de identificar los mecanismos de poder que se articulan en las estructuras digitales para luego desafiarlas con inéditas y creativas prácticas de lucha y de resistencia algorítmica (Treré, 2020).

Si bien, la tecnopolítica es un camino posible de resistencia, mostrado por movilizaciones sociales como el $15 \mathrm{M}$ y el feminismo, es importante reconocer que también es un campo en disputa. De tal forma, no podemos dejar de examinar los movimientos autoritarios, ultranacionalistas, xenófobos, machistas y homófobos, los cuales son parte de toda una amplia gama de movimientos "reactivos" (Ullán, 2016:6670) de extrema derecha, los cuales han hecho también un uso intensivo de las TIC, dando lugar a lo que Julián Macías (2021) denomina el paso del "ciberactivismo al tecnofascismo" (Candón-Mena y Montero-Sánchez, 2021, pp. 35). En este nuevo escenario tecnológico, es entonces importante el estudio de estas disputas políticas y, sobre todo, de los activismos que intentan descifrar y subvertir las lógicas algorítmicas 
en beneficio de la agenda de los grupos subalternos, así como de las comunidades que hacen uso de estos espacios desde los márgenes y de quienes emprenden luchas contra hegemónicas para diseñar políticas públicas que recuperen los espacios del Internet.

A través los trabajos aquí presentados, nos interesa sobre todo mostrar cómo podemos encontrar en el uso común de las plataformas, alternativas a las lógicas de privatización y cercamiento, las cuales representan grietas importantes a la estructura hegemónica. De tal forma, nos interesa unirnos a las conversaciones de los feminismos descoloniales, las cuales buscan imaginar posibilidades de existencia y resistencia del cuerpo colectivo, para brindarnos un atisbo de futuros distintos a los escenarios apocalípticos y distópicos que derivan cuando simplemente extrapolamos el actual estado de las cosas (Haraway, 2020).

\section{Contenidos del monográfico}

En este monográfico se presentan 5 artículos que discuten y reflexionan acerca de estos fenómenos sociotécnicos de violencia y resistencia. Se presentan casos que muestran la reconfiguración de los sistemas de opresión como es la violencia digital que se despliega en contra de las colectivas feministas, las prácticas neocoloniales insertas en el diseño de los videojuegos que incentiva el Banco Mundial, la disputa de sentido emprendida por los grupos antiderechos que utilizan los lenguajes vernaculares de las plataformas sociodigitales para adquirir visibilidad. Pero también, se exponen prácticas de agencia digital que utilizan las mujeres mexicanas para construir los encuadres contrahegemónicos del feminicidio y se rescatan originales prácticas digitales de resistencia colectiva para la pervivencia de las teologías afrodescendientes en Sudamérica.

En el artículo titulado Discurso colonial en videojuegos serios y posibilidades para la decolonialidad en terceros espacios, la investigadora Amanda Rodríguez Espínola realiza un análisis crítico del imperialismo mediático que se articula en las retóricas y en la arquitectura de las tecnologías digitales de los juegos de video en general y en especial, de los llamados "juegos serios" que son aquellos que tienen objetivos educativos y que frecuentemente son creados bajo el patrocinio de organismos internacionales; como es el caso de EVOKE que fue diseñado por encargo del Banco Mundial para fomentar la empatía e innovación social en jóvenes de entre 14 y 24 años. Este juego de video en línea fomenta la creación de redes internacionales de jugadores que intentan prototipar la solución de una problemática social en un lapso de tiempo determinado. La autora hace especial énfasis en la versión Urgent EVOKE que se enfoca en el análisis de las problemáticas de África Subsahariana. Una de las 
principales aportaciones que hace Rodríguez Espíndola a los Estudios del Juego y a los Estudios del Cambio Social, es revelar el discurso civilizatorio que subyace a estas iniciativas que despliegan retóricas desarrollistas y neocoloniales que terminan siendo enarboladas por jugadores del norte global pues los jóvenes africanos tienen dificultades para acceder de forma continua a la tecnología digital y a Internet. La investigadora hace un llamado para fomentar la politización de la categoría empatía, por medio de procesos educativos que cuestionan la colonialidad del poder. Presenta el caso de dos juegos alternativos - Never Alone y Mulaka - que, diseñados desde cosmovisiones indígenas de América, subvierten las retóricas desarrollistas neoliberales y fomentan un respetuoso diálogo intercultural entre los participantes del videojuego en línea.

En su artículo Templos Digitales. Grupos Afroumbandistas argentinos en Facebook, Pablo Maximiliano Ojeda nos muestra cómo las comunidades religiosas pueden (re)apropiarse de espacios hegemónicos para (re)construirse y (re)organizarse. De tal forma, el autor ilustra cómo las diásporas religiosas africanas en América Latina que han crecido al margen de las religiones institucionales predominantes como el cristianismo, el judaísmo y el islam, utilizan los espacios de internet para generar vínculos que trascienden lo local. Lo anterior a través de la creación de grupos con intereses tan diversos como el debate de temas vitales, el humor, la difusión de imágenes y la venta de servicios. También esta interacción permite la búsqueda de templos, así como el compartir experiencias y dudas sobre las prácticas de la doctrina umbandista o comparar precios de las obligaciones y rituales. A grandes rasgos, esta etnografía digital ilustra de manera clara un potencial emancipatorio de las redes en el plano espiritual que resulta interesante por ser una dimensión poco explorada de la tecnología.

La investigadora Lidia García González en su artículo Movimientos feministas en México: Prácticas comunicativas digitales y riesgos, presenta desde una perspectiva sociocultural, las dinámicas de agencia digital incrustadas en las prácticas comunicativas de la acción colectiva feminista en México y aborda también los riesgos que enfrentan las activistas al desplegar sus estrategias tecnopolíticas. La autora da cuenta de estos hallazgos a partir de una investigación etnográfica que incluyó 16 entrevistas profundas a mujeres militantes de 9 colectivas creadas entre el 2016 y el 2021. La investigadora destaca y describe las prácticas de agencia y los protocolos de autocuidado que las jóvenes han elaborado para sortear la vigilancia y violencia digital. Prácticas que aminoran las vulnerabilidades que enfrentan como activistas en un contexto de impunidad, de animadversión estatal y de crecimiento exponencial del crimen organizado. Una de las principales aportaciones de García González radica en el profundo ejercicio etnográfico realizado, el cual permite recuperar las experiencias 
de las mujeres en primera persona y comprender de mejor manera, el impacto del activismo digital en el feminismo contemporáneo.

Por otro lado, María Candelaria Sgró Ruata, en su texto titulado Sexualidad, activismo conservador y redes socio-digitales, analiza el uso de las plataformas por parte de grupos reaccionarios para contrarrestar los avances en la ampliación de derechos para la comunidad LGBTQI+y para las mujeres. Partiendo de los discursos en torno a los debates parlamentarios sobre el matrimonio igualitario y el derecho a decidir en Argentina en 2010 y 2018 respectivamente, el artículo da ejemplos claros de cómo los sectores de ultraderecha han intentado resignificar en las redes, las insignias de la diversidad y del movimiento feminista. Destaca por ejemplo cómo el movimiento provida adopta el pañuelo azul en respuesta a los pañuelos verdes distintivos de la lucha por el aborto legal y seguro, así como la insistencia en una construcción biologisista del matrimonio a través de la difusión de imágenes que lo presentan como únicamente heterosexual y enfocado en la reproducción. En general, el artículo argumenta por la importancia de entender las plataformas como espacios de debate público, en donde los grupos ultraconservadores, si bien no presentan ningún argumento nuevo, sí se renuevan para hacer frente en estos nuevos entornos. También podemos derivar de este texto la importancia de concebir lo común como una práctica de uso del espacio que, al tener potencial para articular la subversión, también se convierte en objeto de nuevas violencias y agresiones.

Finalmente, la investigadora Carolina Hernández Garza nos presenta su trabajo titulado Narrativas en red: dominación o agencia en discursos de Twitter y YouTube frente al fenómeno del feminicidio en México, en el cual realiza un estudio de caso para mostrar la agencia feminista que surge en las redes sociales frente al crecimiento alarmante de feminicidios en México. El artículo analiza los encuadres utilizados en los contenidos que exigen justicia en Twitter y en YouTube por el feminicidio de la joven Monserrat Bendimes Roldán asesinada en abril del 2021 por parte de su pareja sentimental Marlon Botas. A partir de la propuesta tecnofeminista de Wajman (2006) y del pensamiento decolonial de Rita Segato (2016), la autora reflexiona sobre la importancia que tiene la agencia feminista para valerse del carácter sociotécnico de las redes sociales y hacer frente a la voluntad de indistinción que suele desplegarse en los medios tradicionales que se resisten a utilizar el término feminicidio y encuadran estas tragedias como asuntos privados en lugar de temas de interés público. Hernández Garza utiliza métodos y técnicas digitales para indagar si los mensajes feministas en Twitter y en YouTube enfrentan los códigos hegemónicos y si las tácticas tecnofeministas logran abrir espacios de resistencia. Una de las principales aportaciones de este trabajo, es que permite comprender que las resistencias digitales se despliegan de forma diferenciada en las redes sociodigitales. Mientras que en 
Twitter el encuadre feminista toma mayor visibilidad, en YouTube se recrean las violencias y las revictimizaciones.

Esperamos que las y los lectores de Virtualis consideren interesante la lectura de estos textos, y que la originalidad de sus aportaciones nutra sus reflexiones e intereses académicos, a la vez que les permita, recordando el ensayo de Silvia Rivera Cusicanqui, imaginar que otros mundos son posibles (Rivera Cusicanqui, 2018).

\section{Referencias}

Braidotti, R. (2015). Lo posthumano (J.C. Gentile, Trans). Gedisa. (Obra original publicada en 2013).

Braidotti, R. (2020) El conocimiento posthumano (J. Ibarz, Trans). Gedisa. (Obra original publicada en 2019).

Candón-Mena, J., \& Montero-Sánchez, D. (2021). Más allá del ciberactivismo. El complejo escenario de la tecnopolítica contemporánea. En: J. Candón-Mena y D. Montero-Sánchez (eds.), Del ciberactivismo a la tecnopolítica. Movimientos sociales en la era del escepticismo tecnológico (pp. 23- 46). Comunicación

Social Ediciones y Publicaciones

Cusicanqui, S. R. (2018). Un mundo ch'ixi es posible: ensayos desde un presente en crisis. Buenos Aires: Tinta limón.

De Kosnik, A. \& Feldman, K. (2019). \#identity: Hashtagging Race, Gender, Sexuality, and Nation. University of Michigan Press

Dragiewicz, M., Harris, B., Woodlock, D. \& Salter, M. (2021). Digital media and domestic violence in Australia: essential contexts. Journal of Gender-Based Violence 5 (3), 337-393. DOI:10.1332/239868021X16153782923978

Ferrando, F. (2020). Philosophical posthumanism. Bloomsbury Academic.

Foucault, M. (2001). Historia de la sexualidad (Vol. 1). siglo XXI.

Fraser, N. (2020). Los talleres ocultos del capital. Un mapa para la izquierda. (J.M. Madariaga y C. Piña, Trans). Traficantes de sueños.

Girardi, E. (2019). Digitalización, política e inteligencia artificial. ¿Qué futuro podemos esperar?, Nueva Sociedad, 283, 75-81.

Hill, P., \& Bilge, S. (2000). Interseccionality. Polity Press.

Haraway, D. J. (2020). Seguir con el problema: Generar parentesco en el Chthuluceno (Vol. 1). Consonni.

Lugones, M. (2014) Género y descolonialidad. Signo.

Mejías, U., \& Couldry, N. (2019). Colonialismo de datos: repensando la relación de los datos masivos con el sujeto contemporáneo. Virtualis, 10(18), 78-97. 
Organización de las Naciones Unidas (2020, 15 de junio). Las compañías tecnológicas y de redes sociales se lucran a costa de información errónea y discriminación, afirma experta. Noticias ONU. Recuperado el 20 de abril, 2021 de https://news.un.org/es/story/2020/07/1477531

Ricaurte, P. (2019). Data Epistemologies, The Coloniality of Power, and Resistance. Television \& New Media, 20(4), 350-365. DOI:10.1177/1527476419831640

Segato, R. (2016). La guerra contra las mujeres. Traficantes de Sueños. Madrid.

Toret, J. (2015). Una mirada tecnopolítica al primer año de Podemos. Seis hipótesis. Teknokultura, 12(1), 121-135.

Treré, E. (2016). Distorsiones tecnopolíticas: represión y resistencia algorítmica del activismo ciudadano en la era del 'big data'. Trípodos, 39, 35-51.

Treré, E. (2020). Activismo mediático híbrido. Ecologías, Imaginarios, Algoritmos. (E.C. Montaña, Trans.). FES Comunicación (Obra original publicada en 2019).

Van Dijk, T. (2016). Dominación étnica y racismo discursivo en España y América Latina. GEISA.

Van Dijck, J. (2020). Seeing the forest for the trees: Visualizing platformization and its governance. New Media \& Society. DOI:10.1177/1461444820940293

Villa-Nicholas, M. (2020) Data body milieu: the Latinx immigrant at the center of technological development, Feminist Media Studies, 20(2), 300-304, DOI: $10.1080 / 14680777.2020 .1720351$

Zheng, Y. \& Walsham, G. (2021). Inequality of what? An intersectional approach to digital inequality under Covid-19, Information and Organization, 31(1), DOI: 10.1016/j.infoandorg.2021.100341.

Wajcman, J. (2006). Tecnofeminismo. (M. Martínez, Trans). Ediciones Cátedra. (Obra original publicada en 2004).

Winner, L. (1983). Do Artifacts Have Politics? In D. Mac Kenzie et al (eds). The Social Shaping of Technology. Open University Press. 